\title{
Escutando a voz de Meschonnic
}

\author{
Cristina Henrique da Costa
}

UNICAMP

\begin{abstract}
Resumo
O presente artigo procura analisar alguns aspectos da argumentação de Henri Meschonnic em Critique du rythme, tentando mostrar que ela se apóia na decisão de não dissociação entre os diversos registros discursivos habitualmente separados uns dos outros. Tenta-se aqui compreender de que modo esta decisão, que não está a serviço de um estilo literário, e sim de uma ideia diretriz - a do sujeito - desenvolve-se eficientemente. É porque o sujeito está na fonte dos discursos que ele necessariamente tem expressão em diversos gêneros. Da mesma forma, por ser a condição de possibilidade de todo discurso sobre o sujeito, só a decisão de continuidade entre a fala teórica, a tomada crítica e o pensamento poético, é capaz de tornar audível a função organizadora subjetiva dentro da linguagem. Desta maneira, o próprio discurso de Meschonnic sustém-se ao mesmo tempo num esforço de crítica das idéias preconcebidas sobre a linguagem e a poesia, e num esforço teórico-poético para repensar o discurso e o sentido. Sob este ângulo, são então abordadas as noções poéticas de ritmo, de oralidade e de voz, tentando o artigo mostrar a grande originalidade e o poder de transformação que tais noções imprimem ao olhar da teoria literária sobre si mesma.
\end{abstract}

Palavras chave: ritmo; discurso; historicidade; sujeito.

\section{Résumé}

Le présent article cherche à analyser quelques aspects de l'argumentation d'Henri Meschonnic dans Critique du rythme, en essayant de montrer qu'elle repose sur la décision de la non dissociation entre différents registres discursifs habituellement séparés. On tente de comprendre ici sous quel mode cette décision, qui n'est pas au service d'un style littéraire, mais au service d'une idée directrice - celle du sujet, déploie son efficacité. C'est parce que le sujet est à la source des discours, qu'il ne peut que se décliner en divers genres. De même, parce qu'elle est la condition de possibilité de tout discours sur le sujet, la décision de continuité entre le propos théorique, la prise critique, et la pensée poétique est seule capable de rendre audible la fonction organisatrice subjective au sein du langage. Le propos de Meschonnic est ainsi soutenu en même temps par un effort critique qui remet en cause des idées reçues sur le langage et la poésie, et un effort théorico-poétique pour penser à nouveaux frais le discours et le sens. Sous cet angle, sont alors abordées les notions poétiques de rythme, d'oralité et de voix, et on s'attache à montrer leur grande originalité et leur pouvoir de transformation du regard de la théorie littéraire sur elle-même.

Mots-clés : rythme; discours; historicité; sujet. 
1. MESCHONNIC, Henri.

Politique du rythme, 1995, p. 9.
Dans le bruit qui emporte chaque jour le contemporain au Service des Urgences, j'essaie de penser ce qui ne fait aucun bruit, et qui apparemment n'a aucune urgence, mais qui manque, au point que son silence même s'entend sous les discours de luxe. J'essaie de penser une pensée du sujet comme une politique du sujet ${ }^{\text {. }}$.

A voz original e complexa de Henri Meschonnic não é qualquer uma: atribui-se desde o princípio a tarefa de fazer o que diz estabelecendo uma continuidade subjetiva que aproxima seus discursos teóricos dos críticos e dos poéticos. A busca do contínuo, característica linguística de todo discurso, qualidade teórica dos obstinados, e virtude ética dos fiéis a seus princípios define não só o perfil geral do trabalho de Meschonnic como também o estilo combativo de sua escrita. Meschonnic diz tudo desde o início para poder demonstrar que não basta dizer, e que a missão de sua linguagem é fazer. Por isso, não é fácil penetrar no jato poético das setecentas páginas de Critique du rythme e das seiscentas de Politique $d u$ rythme, cuja lógica consiste em afirmar, praticamente a cada passo, que a linguagem é una, dizendo-se justamente isto numa linguagem única e contestadora de qualquer outro gênero. É com ritmo lírico, crítico, polêmico e teórico, tudo no decorrer do mesmo discurso, que se conquista este território da unicidade linguística, solo de uma nova concepção de literatura. E de fato, através de certa linguagem, define-se como continuidade subjetiva o que está na base da demonstração do funcionamento real da linguagem, demonstração que não funcionaria se não praticasse o que pretende demonstrar, numa atitude de total coerência em relação ao objetivo fundamental: provar como a linguagem é produção de sentido no discurso, e como o discurso, seja qual for, é subjetivo.

O sujeito, na voz de Meschonnic, define-se no discurso e duplamente: como posição autotélica e como posição intersubjetiva, uma não existindo sem a outra, de maneira que nisto consiste o segredo de um discurso que alcança ser por um lado argumentação crítica, tomada de posição e definição de oposição, e por outro lado invenção de si próprio. Nada se inventa sem oposição e posição; nada toma posição sem esforço de invenção. Neste movimento, será preciso fisgar primeiro o desejo de profunda contestação da separação entre os gêneros teórico e poético, analisada e explicada como domínio indevido de certo pensamento filosófico que pretende obter por fora a divisão, embora obtenha apenas certa definição equivocada 
e tautológica do poético, enquanto previsto e previsível de antemão. Logo em seguida, será preciso entender que a polêmica não é contra a filosofia em geral, e sim contra os discursos filosóficos que andam circulando; do contrário, tratar-se-ia de uma polêmica filosófica, atitude que para Meschonnic, precisamente, não pode existir sem contradição. O que há, é uma voz clamando que, independentemente das regras do pensamento filosófico, toda prática da linguagem põe em ato uma teoria da linguagem.

Neste sentido, a voz de Meschonnic de fato fala, ou pelo menos poderia falar a todos os que se interessam por teoria, crítica e poesia, embora quando fale, defenda e pratique um modo discursivo inabitual, o qual, por imprevisto e diferente, talvez não possa ser tão imediatamente audível, exatamente porque merece ser escutado. Pois a lógica do discurso de Meschonnic consiste em afirmar que versa sobre algo que só poderá ser entendido quando forem elucidadas e ouvidas as razões que o impedem de ser entendido. Quem quiser lê-lo, que desde sempre o faça sabendo que a ideia mestra - o fio condutor, é que a necessária continuidade entre os discursos, elemento seminal do modo de ver de Meschonnic, fundamenta-se numa concepção de subjetividade que em tudo se opõe à metafísica do sujeito, sem, no entanto, deixar-se vencer e convencer pelas posições desconstrutivas, que segundo ele são apenas aparentemente inimigas desta mesma metafísica da subjetividade ocidental. Na verdade, a metafísica, presente ou ausente, é inimiga do sujeito na própria medida em que o define como signo, e esta definição, ao estar ainda na base da desconstrução da metafísica, mantém a conivência entre discursos que na realidade não se opõem, posto que não chegam a reconhecer a raiz subjetiva incontestável da linguagem enquanto discurso, e não enquanto signo. Por isso, Meschonnic afirma por sua parte: "le théorique est un mode spécifique du subjectif”2.

Antes de concluirmos apressadamente que a afirmação acena em direção da multiplicidade fértil do pensamento esta conclusão virá a seu tempo -, entendamos primeiro que ela vem a significar o seguinte: sendo mesmo e concretamente função de nossa radical historicidade (determinada pela posição subjetiva, e igualmente determinante para ela), as teorias no fundo dividem-se apenas em duas categorias: as que trabalham para a continuidade dos discursos, produzindo escritas que praticam a historicidade do viver-escrever, e as que encobrem esta continuidade, praticando a metafísica da origem da linguagem. Nossa radical historicidade é feita desde sempre da força impetuosa de nossos múltiplos discursos, em fluxo vital, contínuo subjetivo. E enfrenta a camisa de força que os pretende reduzir à repetição do movimento, à obsessão da origem que - como o mar de João Cabral e sua carne vidrada, de
2. MESCHONNIC, Henri.

Critique du rythme, 1982, p. 61. 
3. MELO NETO, João Cabral. Obra completa, 1994, p. 112.

4. MESCHONNIC, Henri. Critique du rythme, 1982, p. 69. estátua, seu silêncio alcançado, à custa de dizer a mesma coisa ${ }^{3}$ - não quer deixar o fluxo fluir.

Repita-se: de chofre, a questão de Meschonnic não é estabelecer fronteiras genéricas entre o teórico conceitual e o prático poético, nem tampouco afirmar $o$ fato da confusão dos gêneros e da impossibilidade das fronteiras. Tanto uma quanto outra coisa dependeriam do reconhecimento do primado de certa instância discursiva capaz de auto fundar-se como pensamento sobre a linguagem, fora da linguagem. Mas o objetivo, isto sim, é questionar a estratégia - isto é, a política e o funcionamento dos discursos encobridores de historicidade, os quais precisamente não se limitam a um gênero discursivo, operando ao contrário em muitas áreas: filosofia, teoria, linguística, crítica, poesia. Obviamente, frente àquilo que ele considera claramente como uma investida política geral contra a subjetividade, não se trata para Meschonnic de construir um discurso da verdade do sujeito que incorra no erro performativo de aceitar a lógica do jogo no campo do inimigo. Como se disse, só existem duas estratégias discursivas, e a de Meschonnic é a outra. Pois há a estratégia das teorias tradicionais, que de múltiplas formas é a estratégia do signo; e há a que adota posições críticas, e sob a forma de uma única estratégia do sujeito, abre-se para as infinitas formas do discurso subjetivo. Por aí já se vê: a subjetividade, característica seminal do homem falante e falando, não pode ser provada pela existência de seu signo - não é conceito nem ausência de conceito. Antes de tudo, expõe-se o enjeu, "parce que celui-ci est le cadre et l'orientation du conflit, qui determine les termes"

\section{Ritmo poético}

Trazida então a questão do subjetivo para o campo da poesia: ela não é tampouco sua origem, devendo-se concluir que, mais exatamente, é necessário trazê-la para o campo dos poemas feitos e do que os poemas fazem visto que, ouvindo bem Meschonnic, a estratégia do sujeito, tão vital para os poemas, torna impossível definir algo como a Poesia. Nos poemas, há continuidade entre sua teoria e sua prática, pois eles necessariamente praticam uma das duas estratégias referidas. É através do reconhecimento de uma ou outra estratégia que se exerce, então, o juízo de Meschonnic, sempre a respeito dos poemas, e nunca da Poesia. Não nos enganemos portanto: o que está sendo proposto, longe de se definir como problematização conceitual do normativo, consiste antes num original questionamento poético-subjetivo das normas conceituais vi- 
gentes, inclusive das que se afirmam como problematização.

Uma vez situado o quadro geral do discurso meschonniqueano, vale a pena penetrar no mecanismo complexo de sua argumentação. A voz de Meschonnic torna-se audível, de fato, pelo prisma de certa oposição dinâmica, produtiva reflexivamente, entre a teoria do signo e a teoria do ritmo, tal como se definem na Critique du rythme:

Dans la téorie du signe, la langue est première et le discours est second. Il ne peut pas en être autrement. Le discours y est un emploi des signes, un choix, une série de choix dans un système des signes pré-existant (...) Dans la théorie du rythme (...) le discours n'est pas l'emploi des signes, mais l'activité des sujets dans et contre une histoire, une culture, une langue, - qui n'est jamais que discours $(\ldots)^{5}$.

O movimento argumentativo da Critique de 1982 é, neste sentido, um pêndulo que exerce um movimento de vaivém entre o esclarecimento dos pressupostos (preconceituosos) da ideologia do signo e a observação empírica do funcionamento subjetivo real da linguagem. Embora demonstre seu apego pelo empírico - "mon travail est constamment dans l'empirique"6, diz ele, Meschonnic afirma também, e até por isso mesmo, que o empírico tornou-se inaudível, por causa da impregnação da ideologia do signo, que estrategicamente vem obscurecendo nossa atual relação com a linguagem. Daí a necessidade da crítica. Levando em conta este mecanismo, o argumento reflexivo parece-me dominante no raciocínio: trata-se de nunca separar conceitualmente o teórico do poético, partindo do princípio que a separação, muito longe de ser natural na linguagem, pressupõe ao contrário uma decisão prévia quanto à finalidade da poesia, e crer nesta precedência da finalidade poética é decretar de antemão a própria separação, substituindo o pensamento crítico sobre a linguagem pela ilusão da definição tautológica do já definido.

A este equívoco do signo, associado de uma forma ou de outra à ideia de essência da linguagem, escapa-se pensando a partir da produção de sentido nos discursos poéticos que aí estão, numa visão antropológica abrangente da linguagem como discurso humano e do homem como falante - uma visão, porém, que só é tornada visível após o necessário desvio crítico.

Esta peculiar abordagem das diversas discussões sobre a linguagem, que em todos os níveis da argumentação desenvolve-se como démarche reflexiva - elucidação de estratégias, crítica da estratégia, prova empírica, alternativas e novas estratégias -, produz certo inegável alargamento dos horizontes. Quanto à questão poética mais precisamente, está em jogo, para Mes-
5. Ibidem, pp. $70-71$.

6. Ibidem, p. 51. 
7. MESCHONNIC, Henri.

Politique du rythme, 1995,

p. 481.

8. Ibidem, p. 378.

9. Ibidem, p. 374.

10. Ibidem, p. 9. chonnic, certa tradição que ele qualifica de grega, atribuidora de excepcionalidade aos poetas e filósofos - abusivamente; está ainda em jogo a veementemente contestada conservação deste modelo em teorias da modernidade, as quais, repetindo uma atitude tautológica da mais pura antiguidade ocidental, e reduzindo o foco cultural através do qual se abordam os fenômenos dos discursos poéticos, impede a fluência da única modernidade possível e real, que mergulha raízes na radical historicidade humana. Modernidade esta que, longe de ser fruto e fato da excepcionalidade de poucos, está igualmente longe de ser a falta individualista de normas, como crê equivocadamente o contemporâneo: "Ceux qui acceptent le présent, qui pensent avec, [...] ils font semblant de le précéder en le suivant, ouvrez la télé pour les voir, le contemporain est content" ". A modernidade meschonniqueana, inversamente, constitui a experiência do tempo enquanto enunciação dos sujeitos, e aprimora-se particularmente no ritmo que organiza o discurso em posição de historicidade. Isto explica que Meschonnic possa afirmar: "je définis la modernité, après une critique de ses acceptions anciennes, comme l'activité continue d'une forme-sujet, la découverte de sa propre historicité comme une présence au présent"8.

Em suma, fazer da poesia uma linguagem outra, à margem, única e exclusiva depositária da verdade, incompreensível, inefável, irracional, é sempre ao mesmo tempo continuar filosofando essências, buscando equivocadamente filosofemas, filosofando contra o poema enquanto linguagem. É, em outras palavras, submeter-se à estratégia do signo:

Le signe est le lieu commun de tous ces modes de pensée. C'est de son instrumentalisme que toutes ces sémiosophies tirent un anti-instrumentalisme, toujours le même, qu'elles lui opposent et qui dans ce jeu de rôles est nommé poésie. Cet irrationnel du signe est son compagnon polaire. ${ }^{9}$

Devemos ler que esta cultura de rompimento interno à linguagem subsiste portanto até mesmo nas ideologias que banalizam o poético sujeitando-o à lógica de sua instrumentalização didática, linguística e conceitual. Às diversas ideologias do rompimento - apenas superficialmente opostas, Meschonnic dá o nome de dualismo, onde ele enxerga sempre uma política aristocrática. Romper pelo discurso com quem rompe a linguagem é portanto também uma tarefa política, de revide contra o caráter duvidoso do ideal de poeta excepcional, ao qual irrefletidamente prestamos vozes como se houvesse outra linguagem ou outra legibilidade da linguagem, algo como alguma antilinguagem, mas algo que, na verdade, está sempre a serviço de um único encobrimento do sujeito. Ele, o sujeito, é o assunto do pensar "la démocratie du poème" 10 . 
Para voltar ao poeta: o louco, o profeta, o maldito, o cego, o puro, o pensante, o racional, o professor ou o gênio, nenhum deles atinge qualquer conhecimento superior fora dos poemas que eles, vários, muitos, fazem e que, ao fazerem, fazem alguma coisa à linguagem, produzindo significâncias, ou seja, ritmos subjetivos que desautorizam a hierarquização dos níveis de significação no poema, e que recusam a referência a critérios diretamente oriundos de alguma estratégia do signo. Entre eles: primado do significante, primado da forma, primado do significado, verdade etimológica, realização de um gênero, etc. Pelo mesmo caminho, ao definir a tarefa transformadora do poema (fazer algo à linguagem) através de sua observação crítico-empírica, está se afirmando sua dimensão subjetiva e histórica. Pois não há como o poema fazer alguma coisa à linguagem sem fazer algo à dimensão coletiva em posição de historicidade. Por isso, poemas são vitais sem serem vitalistas, e têm a ver com todos, como a linguagem, independentemente do poeta excepcional arfando no cimento na beira da morte ${ }^{11}$. Mesmo nos casos em que o poeta se vê excepcionalmente ressentido com a política opressora do signo contra o ritmo do sujeito. Meschonnic recomenda, em qualquer caso, que se saia disso.

Mas afirmá-lo com o discurso não é tarefa simples, na medida em que certa deformação da linguística, ela também contaminada pela estratégia do signo através do formalismo, do estruturalismo e da semiótica, inscreve nos hábitos de pensar reflexos semióticos tão eficientes que alcançam fingir que são a ciência da linguagem, e enquanto tal, que ditam de fora o acesso à compreensão do funcionamento tanto da linguagem quanto da antilinguagem do poeta. Ou seja, a política do poeta excepcional é amiga da estrutura, ambas ocultando, por um processo de naturalização da linguagem, aquilo que, ao contrário, é no entanto a historicidade própria dos sujeitos discursantes, incapazes de falar por referência à língua como se ela fora alguma estrutura superior, sustentadora de seus signos.

\section{Ritmo linguístico}

Por isso, exatamente porque a linguagem é uma coisa só, a desmistificação da Poesia implica primeiro numa releitura da linguística, para desembaraçá-la de sua parte na estratégia do signo. É que como o processo de ocultação é multiforme, só se chega a compreendê-lo quando se aceita uma passagem pela teoria linguística, onde também se sofre a deformação pelo signo que não deixa enxergar a linguagem. Ora, não é difícil constatar que esta, inegavelmente, produz sentido sem
11. Aludo aos seguintes versos: "não o nome,/ vivo animal, / planta viva/ a arfar no cimento" (João Cabral de Melo Neto. $O$ funcionário), e "ante a fruta madura/ na beira da morte,/ imóvel no tempo/ que ela sonha parar”. (João Cabral de Melo Neto. As estações) [os grifos são meus]. 
12. SAUSSURE, Ferdinand. Cours de linguistique générale, 1986, p. 106.

13. Ibidem, p. 108. produzir essências, naturezas ou estruturas. Nesta perspectiva, a co-extensão empírica da produção de sentido e da produção de discursos - um não se produzindo sem o outro - é um argumento que possui certa força radial por poder cobrar fidelidade à empiria em todas as áreas discursivas, sem entretanto reduzir a dimensão poética, elevando-a ao ritmo de sua significância.

Quanto à vertente linguística do encobrimento, pela qual se precisa necessariamente passar: não se trata para Meschonnic de denunciar o papel encobridor de subjetividade da linguística em si, e sim, inversamente, de redescobrir, no processo de constituição do próprio pensamento linguístico, a possibilidade de pensar o sujeito, a qual ficou encoberta por discursos exógenos que tiveram interesse em deslê-la. Meschonnic retorna, como é lógico, a Saussure, para lembrar que no Cours de Linguistique générale a linguagem é tratada como sistema e como arbitrário. Seria (e foi) um contra-senso resvalar destes conceitos, para definir a linguagem como estrutura e confundir o arbitrário com a convenção. Pois entre estes pares de conceitos: sistema e arbitrário versus estrutura e convenção a diferença é estratégica e politicamente enorme. Sistema e arbitrário significam que a linguagem só pode ser tratada como tal, não possuindo nenhum fora. Estrutura e convenção postulam a existência de uma instância imutável dominando os signos; e por mais que a instância seja chamada de estrutura, fundamenta-se sempre na existência de uma norma natural escondida por trás de qualquer pensamento do imutável. À norma natural também se refere, negativamente, qualquer convenção. Por isso Saussure afirma claramente que não há nenhuma convenção: “l'arbitraire même du signe met la langue à l'abri de toute tentative visant à la modifier". E logo adiante: "pour qu'une chose soit mise en question, il faut qu'elle repose sur une norme raisonnable"12.

Não ter que se referir a nenhum avesso natural ou a nenhuma estrutura imutável, e não poder fazê-lo, é segundo Meschonnic a condição fundamental que define a historicidade da linguagem humana: os homens falam; não decidiram falar, nem se obrigam a dizer sempre a mesma coisa. Não há origem externa, ou razão de ser ao fato da linguagem. Esta historicidade do falar, diretamente vinculada à noção de arbitrário, já estava reconhecida pelo próprio Saussure: "C'est parce que le signe est arbitraire qu'il ne connaît d'autre loi que celle de la tradition, et c'est parce qu'il se fonde sur la tradition qu'il peut être arbitraire" 13 .

Desta falta de exterioridade da linguagem como um todo induz-se um complemento de definição, que surge como consequência lógica da falta de escolha individual quanto aos signos: trata-se do valor linguístico. Pois, de fato, o caráter indissolúvel - frente e verso, do significado e do significan- 
te não se fixa entretanto no signo como totalidade, porque os próprios signos possuem apenas valor diferencial: "Faisant partie d'un système, (le mot) est revêtu non seulement d'une signification, mais aussi et surtout d'une valeur, et c'est tout autre chose"14. Daí que falar não é musicar com o som, nem se referir a conceitos, muito menos expressar a totalidade na palavra (seja ela disjunta ou conjunta), posto que falar mobiliza o sistema arbitrário como um todo: "les valeurs restent entièrement relatives, et voilà pourquoi le lien de l'idée et du son est radicalement arbitraire" ${ }^{\prime 15}$. Em outras palavras, bem resumidas por Meschonnic relendo Saussure, é o próprio Saussure quem sugere que o arbitrário não se compreende a partir do signo, $\mathrm{e}$ sim a partir de quatro termos que devem ser tomados juntos: valor, sistema, funcionamento e arbitrário.

Não se deve, e sobretudo nem se pode, segundo Meschonnic, confundir sistema e estrutura:

\begin{abstract}
Système, qui est le terme de Saussure, est historique, en ce qu'il ne sépare pas philologie et linguistique (...). Alors que structure est ahistorique, et ne peut que déshistoriciser. En quoi rien n'est plus opposé à Saussure que sa postérité structuraliste" ${ }^{16}$.
\end{abstract}

Mas pode-se, inversamente, explicar esta confusão, lendo-a em sua estratégia, a qual revela ainda outra identificação - mais danosa e perigosa ainda, entre indivíduo e sujeito. Foi porque o estruturalismo não soube pensar a diferença entre indivíduo e sujeito que também não foi capaz de compreender o caráter histórico da linguagem humana. Em outras palavras, a oposição entre língua como estrutura e fala individual, (compensada pela ideologia da escritura excepcional, por exemplo com Barthes), reflete, como é lógico, uma cisão entre indivíduo e sociedade que ressoa na identificação errônea do sujeito (impensável) e do indivíduo. Uma identificação cujo teor fantasioso prova-se pelo próprio funcionamento da linguagem enquanto discurso subjetivo. Meschonnic chega a sugerir a ideia de estruturalistas e marxistas terem sucumbido a uma ilusão burguesa paradoxal; e tudo parece se explicar, se considerarmos que esta identificação/confusão entre indivíduo e sujeito, refletida na dualidade do par indivíduo/sociedade, está a serviço do reino universal da metafísica do signo. Vista pelo prisma do funcionamento histórico da linguagem, esta confusão é ela própria, portanto, um momento histórico que se ignorou como tal, naturalizando-se historicistamente. Pois cabe precisar:

L'historicisme est l'oubli que rien, du langage et de l'histoire, n'est décrit sans observateur, et que l'observation est toujours un rapport qui modifie ce qu'on observe. Qui déborde la pensée claire ${ }^{17}$.
14. Ibidem, p. 160.

15. Ibidem, p. 157.

16. MESCHONNIC, Henri.

Critique du rythme, 1982, p. 29.

17. Ibidem, p. 30. 
18. BENVENISTE, Emile. Problèmes de linguistique générale 1, 1966.

19. Ibidem, p. 258.

20. Ibidem, p. 260.

21. "La forme "il" tire sa valeur de ce qu'elle fait nécessairement partie d'un discours énoncé par “je"”. Ibidem, p. 265.

22. Ibidem, p. 259.

23. Ibidem, p. 266.
Livrando-se desta equivocada visão da linguagem como estrutura, do sujeito como indivíduo e ainda do signo como verdade, tudo graças ao retorno a Saussure, o que se obtém é certa disponibilidade crítica para escutar então as lições de Benveniste, do qual Meschonnic se reivindica claramente, e com razão, porque lhe deve muito. Em Critique du rythme, a referência explícita, desde o começo do livro, é o artigo de Benveniste que analisa a etimologia da palavra ritmo ${ }^{18}$. Mas além disso, o pensamento meschonniqueano em geral filia-se também ao famoso De la subjectivité dans le langage ${ }^{19}$, onde está assente que: "c'est dans et par le langage que l'homme se constitue comme sujet (...) est ego qui dit ego" ${ }^{20}$. Como Benveniste explica, a linguagem enquanto homem falando a outro homem, só é possível na medida em que o locutor assume a posição de "eu" no seu próprio discurso, embora "eu” (assim como "tu” e "ele" ${ }^{21}$ ) não designem um conceito de sujeito, nem tampouco um indivíduo sujeito, senão aquele que, na própria instância do discurso, vem a designar-se ele mesmo como sujeito e produtor da locução. A chave da ideia de subjetividade pode então estar, para começar, nesta constatação da linguística da enunciação de Benveniste, a qual possibilita pensar que a linguagem, desde sempre co-extensiva a qualquer homem e a todos os homens ("nous n'atteignons jamais jl'homme separé du langage et nous ne le voyons jamais l'inventant"22), não deixa de ser perfeitamente co-extensiva ao sujeito. Mas isto não se dá na língua, e sim no discurso: "dans le cadre du discours, qui est la langue en tant qu'assumée par l'homme qui parle, et dans la condition d'intersubjectivité (...)”23.

É exatamente porque ninguém inventa individualmente a linguagem que a subjetividade não precisa de fundamento extrínseco ao discurso que produz e que nela se produz; neste sentido, pela linguagem, a subjetividade tem a ver com todos, sendo sempre função de todos. Longe de se confundir com algum tipo de nominalismo, e muito menos com a fenomenologia da consciência, a definição da subjetividade por Benveniste torna possível recortar a realidade do sujeito como algo que se apreende quando se diz no discurso, e não se apreende fora dele; não se apreende, por exemplo, no signo.

O pensamento do fenômeno de produção de sentido pelo discurso, em posição de radical historicidade e sem vínculo com a natureza, libera para Meschonnic a questão do sentido poético de suas obsessões originárias: para ele, fora do poema enquanto discurso subjetivo, não há origem do poema. Em contrapartida, não existe servidão à língua, na medida em que o discurso não se esgota no signo, e manifesta em sua organização empírica muitos outros fenômenos sem os quais a linguagem humana permaneceria, como no signo, pura abstração. Estes fenômenos tão familiares: acentuação, prosódia, 
sintaxe etc. que se chamam ritmo, embora sejam fenômenos perfeitamente identificáveis empiricamente, são o campo mesmo da produção do sentido ao qual não teremos acesso sem que paralelamente se cumpra mais profundamente, na área do poético, um movimento de crítica e de observação que, estando presente desde o início do pensamento de Meschonnic, a toda hora precisa ser mobilizado.

\section{O ritmo do ritmo}

O que é o ritmo? Começa tudo de novo, pois, de fato, como compreender do que se fala ao falar de ritmo, se a própria noção também está encoberta e contaminada pelas estratégias do signo que se imiscuem na estética, na poética, na estilística? É preciso novamente mostrar que a especificidade do ritmo como linguagem existe somente no discurso e nada compartilha com a música. O preconceito de musicalidade é, ele também, um efeito da ilusão do signo, desaguando na identificação do ritmo com o inefável. Da mesma forma, e pelo mesmo raciocínio crítico, a palavra ritmo não autoriza conceitualmente a afirmação da correspondência estrutural entre as artes, pelo contrário. E de nada serve tampouco o ritmo para os estudos de estilística ou de estética: ele não é a métrica, e não define o gênero poético por oposição à prosa ou a outro gênero poético. Nem a filosofia alcança resgatá-lo numa visão global da essência do movimento.

O que podemos ler por trás deste discurso crítico-empírico? Ou, em outras palavras, e para repetir a pergunta: o que é o ritmo, então? A resposta é complexa, mas por isso mesmo interessante: ao mesmo tempo que, por um lado, o objetivo é demonstrar que o ritmo é uma exclusiva da linguagem, por outro lado precisa-se desconstruir a ideologia da racionalidade do ritmo. A racionalidade está baseada na política da métrica, a qual não consegue se conformar com a existência de produção de sentido incomensurável. E precisa-se, além do mais, desvincular a ideia do ritmo enquanto produção de sentido de qualquer analogia entre o ritmo poético e a ordem cósmica. Esta é regular e natural; aquela, é ordem histórica, movente e subjetiva. Trata-se de fazer do ritmo, em suma, algo co-extensivo ao discurso, como a própria subjetividade, fazendo dele aquilo que se define como forma-sujeito em posição de historicidade:

Je définis le rythme dans le langage comme l'organisation des marques par lesquelles les signifiants, linguistiques et extra-linguistiques (dans le cas de la communication orale 
24. MESCHONNIC, Henri. Critique du rythme, 1982, p. 261. surtout) produisent une sémantique spécifique distincte du sens lexical, et que j’appelle la signifiance: c'est à dire les valeurs, propres à un discours et a un seul24.

Advindo o momento desta definição no discurso mechonniqueano, nada termina, tudo começa, sempre se argumenta ainda e ainda, no fluxo contínuo, na continuidade específica que existe entre crítica, teoria e observação da linguagem. E neste contexto, dois caminhos para a compreensão do fenômeno rítmico parecem ser trilhados; o primeiro, ao qual não me atenho, é amplamente percorrido pelo autor em Critique du rythme, continuando em Politique du rythme, e consistindo numa discussão aberta - enriquecida por invejável cultura teórica, literária e linguística -, com múltiplos representantes do dualismo multifacetado da cultura francesa. Segundo Meschonnic certa ideologia do génie de la langue é absurdamente surda ao ritmo existente nas próprias produções poéticas da cultura francesa, por influência nefasta da estratégia do signo. É, neste aspecto, a própria cultura francesa que precisa se libertar de seus preconceitos.

O segundo caminho está obviamente vinculado ao primeiro, através do tema da contestação da universalidade abstrata da língua: é o caminho que leva ao horizonte sem fim de um discurso teórico sobre o poético que toma definitivamente o partido da historicidade cultural, e que nós, no aqui e no agora, também podemos percorrer sem nenhuma subserviência conceitual. Pois, mais uma vez, na ponta do lápis meschonniqueano, a relação básica entre crítica da universalidade abstrata e observação do real se ramifica, para afirmar estrategicamente que a produção do futuro depende de preservar a diversidade do passado. Neste processo, parece-me da maior importância ressaltar que o projeto de mostrar o quanto o ritmo não é universal, e sim peculiar aos modos de significar, ultrapassa o projeto de crítica da ideologia da universalidade francesa e atinge não menos eficientemente a ideologia da universalidade grego-germânica de Heidegger, tal como Meschonnic nos pinta: um Heidegger, não nos enganemos a respeito disto, persuadido que a verdade, estando na língua, só se diz em duas línguas, mais exatamente na retomada etimológica de uma pela outra.

Ora, em Meschonnic, não existe verdade da língua: marcas acentuais, prosódicas, lexicais e sintáticas neutralizam o fatiamento do discurso, impedindo a separação de níveis, e não havendo o que medir, o ritmo organiza o sentido como atividade do sujeito, como está no estudo da etimologia da palavra ritmo por Benveniste. O ritmo, de fato, o linguista foi habilmente buscá-lo na cultura grega anterior a Platão: 
Les citations suffisent amplement à établir: $1^{\circ}$ que rythmos ne signifie jamais "rythme" depuis l'origine jusqu'à la période attique; $2^{\circ}$ qu'il n'est jamais appliqué au mouvement régulier des flots; $3^{\circ}$ que le sens constant est "forme distinctive"; figure proportionnée; disposition ${ }^{25}$.

Desvinculado, a partir de Benveniste, da significação de cadência e de regularidade que só irá adquirir por influência platônica, o ritmo, isto é, "la forme dans l'instant qu'elle est assumée par ce qui est mouvant, mobile, fluide, la forme de ce qui n'a pas consistance organique" ${ }^{26}$ torna-se em Meschonnic a forma de organização do discurso movente e do que flui, sem totalização, origem, eternidade ou essência, num sentido coerente com seus primeiros empregos, mas, precisamente, independente dele: "rythmos signifant littéralement manière particulière de fluer" ${ }^{27}$.

É neste contexto argumentativo aberto radicalmente ao histórico que tem lugar um novo conceito de oralidade e de vOZ pelo ritmo cuja originalidade eu gostaria de destacar. Trata-se, em Critique du rythme, de dar a estas palavras oralidade e $V O Z$ um sentido especificamente poético e um poder de organização. Por isto, segundo Meschonnic a oralidade não é a situação da fala, oposta à situação de um texto escrito, assim como a voz de um poeta não pode ser a metáfora escondida para falar da verdade do signo. É preciso ouvir a voz, diz Meschonnic, e não, como faz Heidegger, a palavra voz. A voz é ritmo, o ritmo é a oralidade da voz. Engana-se, segundo Meschonnic, quem opõe a fala oral e a escrita, e por isso mesmo devemos rever nossos conceitos de literatura. Pois assim como oralidade é aquilo que organiza em ritmo qualquer produção de sentido - existindo portanto uma oralidade da escrita, visível, por exemplo, na pontuação e nos brancos tipográficos -, a $V O Z$ tampouco se confunde com a realização fônica individual. Uma voz é sempre intersubjetiva, e jamais foi questão de indivíduo. Lembre-se sempre que aquilo que parece mais pessoal na dicção de um poeta é pura tradição: o que seria da dicção Bonnefoy sem a dicção Mallarmé? Indaga Meschonnic. Podemos imaginar dezenas de indagações do mesmo tipo, pois na verdade, a pergunta se aplica a todos os que, justamente, possuem VOZ.

O que está ainda aqui em questão, é a ideia de historicidade da $v O Z$, a qual remete para a historicidade da oralidade e pede, junto com a escuta, uma antropologia histórica da $V O Z$ como fenômeno de linguagem. Sem esta $V O Z$, literatura alguma seria ouvida. Por este prisma, nenhuma antropologia pode dizer algo do presente e do futuro se não atentar ao fenômeno da $v o z$, isto é, da oralidade do dizer - em textos antigos, em discursos de várias dicções e de línguas variadas, em poemas que aí já estão. Neste sentido também, todo poema, não ape-
25. BENVENISTE, Emil. Problèmes de linguistique générale, 1966, p. 332.

26. Ibidem, p. 333.

27. Ibidem, p. 333. 
28. Critique du rythme, p. 299. nas os herméticos, que decididamente não possuem a exclusividade da $V O Z$, todo poema põe em questão especificamente a noção do compreender, e logo, do ouvir a VOZ. Paralelamente, nenhuma antropologia nada dirá do presente e do futuro se não souber da capacidade imprevista da voz, posto que ela é oralidade, isto é, ritmo, ou ainda: organização do discurso pelo sujeito - a quem cabe, (e a ele só) modificar as regras de um discurso através daquilo que ele diz.

Porque há ritmo, há oralidade. Porque há oralidade, há voz e vozes. Para enfim compreendê-lo, recusemos o esquema rígido e metafísico da estética da percepção que, quanto mais separa o olhar da escuta, menos ouve e menos vê: "Il n'y a pas, d'un côté, l'audition, sens du temps, et la vision, sens de l'espace"28. Se é importante para Meschonnic afirmar que ver está na voz dos profetas, desde a Bíblia até Victor Hugo, assim como dizer está na página organizadora dos poemas, e provavelmente também desde a Bíblia até poemas de hoje, é que, antes de tudo, é preciso combater o silêncio sobre o ritmo que vive no entanto presente; é preciso afirmar que o ritmo fez, faz e fará. Com ele, justifica-se o esforço de continuar fazendo e ganha sentido a dedicatória do Critique du rythme. Apaixonadamente: "à l'inconnu". 


\section{Referências}

BENVENISTE, Emile. Problèmes de linguistique générale 1. Paris: Editions Gallimard: 1966.

MELO NETO, João Cabral. Obra completa. Editora Nova Aguilar, Rio de Janeiro, 1994.

MESCHONNIC, Henri. Critique du rythme. Anthropologie historique du langage, Lagrasse : Editions Verdier, 1982.

MESCHONNIC, Henri. Politique du rythme. Politique du sujet, Lagrasse: Editions Verdier, 1995.

SAUSSURE, Ferdinand de. Cours de linguistique générale, Paris: Payot, 1986. 
